\title{
A Plurality of Viewpoints Regarding the Uncertainties of the Agroecological Transition
}

\author{
Danièle Magda, Nathalie Girard, Valérie Angeon, Célia Cholez, \\ Nathalie Raulet-Croset, Régis Sabbadin, Nicolas Salliou, Cécile Barnaud, \\ Claude Monteil, and Nathalie Peyrard
}

\begin{abstract}
The concept of agroecological transition revives debates on how to deal with complexity and uncertainty. While the adaptive approach and its "adjust along the way" principle have been adopted as a relevant general framework to deal with partially irreducible uncertainty, the different approaches to the definition and management of uncertainty are rarely explicitated. In this chapter we highlight the diversity of these stances through brief presentations of research work that is related to agroecology and sustainable development, and anchored in various disciplines (modelling, management sciences, economics, ecology). This gives us a first glimpse of the variety of concepts used to describe uncertainty, characterising nature and the different approaches to manage it. It shows also that these definitions of uncertainties, clearly derived from particular disciplines or school of thought, can be applied together in a more or less complementary way. Finally, we discuss how
\end{abstract}

D. Magda $(\bowtie) \cdot$ N. Girard · C. Cholez

AGIR, Université de Toulouse, INRA, Castanet-Tolosan, France

e-mail: daniele.magda@inra.fr; nathalie.girard@inra.fr; celia.cholez@inra.fr

$\mathrm{V}$. Angeon

URZ, INRA, Petit-Bourg, Guadeloupe, France

Ecodéveloppement, INRA, Avignon, France

e-mail: valerie.angeon@inra.fr

N. Raulet-Croset

IAE de Paris, Université Paris 1 Panthéon Sorbonne, Paris, France

e-mail: raulet.croset.iae@univ-paris1.fr

R. Sabbadin $\cdot$ N. Peyrard

MIAT, Université de Toulouse, INRA, Castanet-Tolosan, France

e-mail: regis.sabbadin@inra.fr; nathalie.dubois-peyrard@inra.fr

N. Salliou $\cdot$ C. Barnaud $\cdot$ C. Monteil

DYNAFOR, Université de Toulouse, INRA, Castanet-Tolosan, France

e-mail:nsalliou@ethz.ch; cecile.barnaud@inra.fr; claude.monteil@ensat.fr

(C) The Author(s) 2019

J.-E. Bergez et al. (eds.), Agroecological Transitions: From Theory to Practice in Local Participatory Design, https://doi.org/10.1007/978-3-030-01953-2_6 
this explicitation of the diversity of approaches to uncertainty contributes to highlighting different ways of defining the agroecological transition itself - especially between determinist or more open-ended approaches-, and identifies interdisciplinary research issues.

\section{Introduction}

Uncertainty and complexity were at the heart of the first debates around sustainable development (Godard 2001; Hubert 2002). Today, the agroecological transition (AET) is once again reviving the full extent of the problem of dealing with the uncertainty tied to the complexity introduced by the joint management of the different dimensions of a change process. There is nothing new about analysing the uncertain, or uncertainty in the broad sense; it has even resulted in the development of fields of research advancing a particular point of view, for instance around the notion of a risk (Motet 2010) or even more recently, ignorance (Roberts 2013; Girel 2016)). Here, we focus on dealing with the uncertainty or, more specifically, the uncertainties, in management processes s.l. involved in the AET. The questions that have emerged around the methods of governance and management of the AET are a continuation of a long-established critical analysis of the bases of the management methods that prevailed prior to sustainable development (Voß et al. 2007). Previously based on the principles of anticipating, predicting, and predetermining goals and means, these management methods followed a "command-and-control" philosophy (Pahl-Wostl et al. 2010) which therefore sought to reduce uncertainty overall (Holling and Meffe 1996). Today, these methods are faced with the necessity of assuming the management of various types of uncertainty that are emerging on the global scale as the result of new sustainability paradigms, and specifically the AET. The uncertainty due to the unpredictable nature of the behaviour of complex managed systems is thus combined with uncertainties tied to the indeterminacy and ambiguity in play in both individual and collective decision processes.

Much research has sought to highlight, design, or implement in the field other "management philosophies" (Hatchuel and Weil 1992) for dealing with uncertainties without reducing the importance of sustainability. Forms of management and governance referred to as "adaptive" have thus become part of this debate (Voß and Bornemann 2011). The founding principle of the adaptive method is that the best strategy when faced with an irreducible uncertainty is to make the best of management experience to adjust along the way (Holling 1978). However, behind this extremely general framework, a wide array of proposals has developed around the way of adapting, and these proposals often have very different ways of dealing with uncertainties without these truly being elucidated. For example, many variants of the adaptive management method have emerged from different disciplines, without, however, providing an analysis of the particular different viewpoints adopted with regard to uncertainties. The significance of these different viewpoints is often relegated to a secondary level, with the focus being instead on the objects/points of 
entry through which the question is posed, or the levels at which it is addressed (concerning an object and its behaviour, on the scale of an action, an individual, or a group). Yet these different proposals or viewpoints, which are sometimes presented as being complementary, have stemmed from epistemologies/paradigms of uncertainty that are radically different or even difficult to reconcile. This lack of explication generates ambiguities from one researcher to the next, especially when they interact within multidisciplinary research initiatives, or in a support capacity. The TATA-BOX project met these criteria exactly, as a process in which a multidisciplinary research team supported local actors (cf. chapter "TATA-BOX at a Glance").

Little work has been done on the diversity of uncertainties and of the ways of dealing with them. Yet they are a structuring element in the analysis and support of the AET, and more broadly, of transformation processes engaging complex systems and multiple interacting dimensions.

This chapter sheds light on the diversity of viewpoints on uncertainty as regards the AET, based the work of researchers in different disciplines (modelling, management science, economics, ecology, etc.) (Girard and Magda 2016). ${ }^{1}$ Each section relates different authors' explication of their relationship to uncertainty in their work. Depending on the author, they draw either on the concepts and approaches of their discipline, or on an approach developed around a given issue. The discussion section offers a synthesis and analyses these different viewpoints to identify elements that may inform reflection on the AET.

\section{Understanding the Agroecological Transition as an Economic Situation of Radical Uncertainty}

Dealing with uncertainty is central in economic analysis, which focuses on the rational behaviour of agents. An abundant literature in neoclassical economics addresses uncertainty probabilistic terms (cf. Postel (2008) for a literature review). In this school of thought, the world in which agents make decisions is known (or partially known) insofar as it can be characterised through a data set (whether objective or subjective data). Agents' decisions are predictable. The complete (i.e. maximum information available) and perfect (i.e. accurate) nature of the information is the cornerstone of this decision-making model, which describes a substantive rationality. In contrast with this approach formalising calculable uncertainty, others have focused on situations of radical uncertainty that do not offer a possibility of predicting economic behaviours (Keynes 1921, 1936; Simon 1964, 1978). The decisions to take demand "a wager on the future" due to the impossibility of presently

\footnotetext{
${ }^{1}$ This chapter is based on the presentations, conversations, and summary of a seminar organised as a part of the TATA-BOX project on 16 February 2016 entitled "Is it possible to adapt to uncertainties in the context of the agroecological transition and how can it be done?" ("Peut-on et comment s'adapter aux incertitudes dans le cadre de la transition agroécologique?").
} 
possessing the information necessary for decision-making as defined by the neoclassical approach. In this case, agents' rationality is qualified as being limited or procedural (Postel 2008). It describes their ability to deliberate, that is, to construct and legitimise their choices.

The AET illustrates this situation of radical uncertainty. It urges people to produce and consume differently. This need to do things differently sets the terms of the change and its management in order to move beyond the conventional production and consumption model. As shown below, it implies differing decision and action logics in a context of greater uncertainty related to the way of redesigning the dynamics of human-nature relations and of legitimising the production and consumption models to promote. Dealing with uncertainty in production and consumption models in the AET aims at answering the following questions: How is uncertainty removed? In other words, what decision-making and action processes are clarified by these agroecological production and consumption models under construction? On what bases are these models legitimised?

Two transition pathways characterised by weak versus strong ecological engagement are proposed to implement new production and consumption systems (Horlings and Marsden 2011; Duru et al. 2014, 2015a). Depending on which of these transition pathways is preferred, their relationship to uncertainty differs. We posit that the construction of production-consumption models with weak ecological engagement is a part of an approach aimed at reducing uncertainty, promoted by a small number of actors whose rules for decision-making and action are based on the production and accumulation of scientific knowledge. By contrast, models with strong ecological engagement aim to explore uncertainty, involving a broader diversity of actors to network and a process of combining/recombining knowledge on multiple scales of time and space.

In its weak version, the AET shares the desire to control nature with the so-called "conventional" model, although through the development of technological artefacts that are more respectful of the environment. It integrates these ecological considerations into existing consumption and production models. Questions relating to the goals and definition of the production and consumption models to construct are therefore clearly identified from the beginning. They are aligned around the principle of promoting technical efficiency to improve production and yields.

These types of agroecological models are underpinned by a logic of reducing uncertainty. They therefore identify decision and action principles that are similar to those of the conventional model, and do not challenge the system of actors in the conventional model or their technico-economic values. The technico-economic efficiency and performance standards inherited from the conventional model control the organisation of the production and consumption of agroecological goods and services. Models with weak ecological engagement can thus emerge from within the economic and social order (ESO) governed according to the principles of industrial rationality (Thévenot 1989; Boltanski and Thevenot 1991). Within this ESO, the functions and roles of the different categories are specified. Large companies manufacture the technological solutions developed by specialised research institutes and used by farmers through predefined procedures. For each of these actors, 
uncertainty presents itself in a very limited form: production questions are identified at the start; and the objectives of the production and consumption models to build are known and are conveyed by a set of technical solutions pertaining to a process of producing and accumulating knowledge.

In its strong version, the AET aims at managing changes in order to effect an indepth transformation of production and consumption models. It thus challenges the capacity and legitimacy of the incumbent system to fulfil society's aspirations. The models to design must however take into account the ecological aspirations that the actors must agree upon, both in their formulation and in the concrete mechanisms of achieving and evaluating them. Nothing allows to predict if agents will be successful in coordinating their goals and their actions - nor within what scale of time or space. Uncertainty is related to individual and collective capabilities to steer the change.

Given the impossibility of predicting the future, the AET places agents engaged in constructing production and consumption models with strong ecological engagement in a situation of radical uncertainty. They have to explore transition pathways by proposing response paths that are concrete in terms of technology, products, production systems, etc. The strong AET is therefore an axiomatic system for action that postulates that it is by exploring uncertainty through experimentation that legitimate production and consumption models can emerge.

This version of the AET breaks with the uncertainty reduction logic and the associated principles of industrial rationale. Agents challenging the incumbent model and positioning themselves in such a way as to promote the emergence and legitimisation of the new are numerous and do not act according to an established ESO. The strong AET renders the conventional model's methods to solve production problems and its evaluation method obsolete. In its strong version, the AET implies the need to break away from a logic of reducing uncertainty, based on the production and accumulation of knowledge by a small number of actors acting within an established ESO. As Crevoisier and Jeannerat (2009) show with regard to industrial activities, it requires a logic of networking a large diversity of actors and of combining/recombining knowledge on multiple scales of time and space.

\section{Analysing New Contractual Forms as an Organisational Response to Behavioural and Technical Uncertainties in Agro- industrial Diversification Supply Chains}

While multiple branches of economics are interested in situations of radical uncertainty (cf. supra), they may nonetheless grant different roles to it. For example, innovation economics sees uncertainty as an opportunity inherent to all processes of change (Pavitt 2005). New institutional economics, on the other hand, is based on the hypothesis that economic actors wish to reduce the uncertainty in which they 
operate (without, however, being able to ascribe probabilities to the occurrence of future events). Uncertainty thus explains the creation of institutions (North 2005). Within new institutional economics, the governance (or transaction cost theory) stream allows to analyse the organisational structures implemented by actors to frame their interactions, taking into account uncertainties that are both "behavioural" and "environmental" (Williamson 1996). Behavioural uncertainty relates to the fact that one of the parties to a transaction can potentially take advantage of the resulting situation of interdependency at the expense of the other; in other words, they can behave opportunistically. Environmental uncertainty relates to the events (or exogenous elements) that can potentially affect the transaction but which are not dependent on the parties to it. These can include unpredictable climactic aspects as well as variations in the cost of raw materials on the global market. Implementing contractual forms that are more coordinated than the market restricts the actions of stakeholders, by defining "an agreement under which two parties make reciprocal commitments in terms of their behaviour - a bilateral coordination arrangement" (Brousseau and Glachant 2008). At the same time, these contractual forms can encourage the specific investments necessary for value creation and innovation. Ultimately, the contract is a compromise between security and flexibility. Securing the investments of the parties appears to be necessary, considering that opportunistic behaviour is not eliminated; moreover, maintaining flexibility in interactions appears to be fundamental in a context of change. In a static approach based on the transaction cost theory, uncertainty is ultimately an attribute of the transaction that determines actors' organisational choices. However, as Yvrande-Billon and Saussier (2011) have pointed out, several attempts have been made to expand this framework in order to analyse how the organisational forms chosen also support learning on production techniques. Analysing contracts from this angle introduces a change in stance: the organisational form is thus understood as a way of having an impact on the state of technical knowledge, and hence of reducing the level of uncertainty around production techniques and consequently the transaction.

While to date, the vertical coordination of agri-food supply chains has mainly been studied in relation to the emergence of a quality economy on globalised markets, the AET revives the question of the coordination between actors in an uncertain context. In particular, the uncertainty surrounding production practices raises questions on the way that the chosen organisation methods contribute to creating and transmitting the technical knowledge for production. Reintroducing new species into crop systems is a prime example of this, since it simultaneously involves uncertainties related to the development of new commercialisation supply chains, and uncertainties related to the change in practices. In large-scale farming, a diversity of contracts structures exchanges between farmers, storage organisations, and transformation industries. In this diversity, we studied production contracts ${ }^{2}$

\footnotetext{
${ }^{2}$ Production contracts are arrangements that define the conditions for selling products but which also allow for anticipation and structuring, to varying degrees, of the production conditions of the crop. In this sense, they are different from classic sale contracts found in the sector, which only define the conditions for putting the seed on the market and for compensation. According to a
} 
supporting the development of diversification supply chains and the way that they allow actors to coordinate with one another in a context of change and uncertainty.

The case study of a fava bean supply chain is illustrative of a change in crop systems moving towards a greater diversity of farmed crops, which is a key principle of agroecology (Altieri 1999). Moreover, as a pulse crop, the cultivation of fava beans has specific agro-environmental effects (related to the fixation of atmospheric nitrogen and decreasing greenhouse gases) (Jensen et al. 2010). This supply chain, initiated by a processor in western France, is emblematic of a form of governance combining vertical contracts and collective territorial governance within an association. The association, which groups together the manufacturer and several of its suppliers (cooperative or private storage organisations), appears to be complementary to the formal contracts signed between the manufacturer and each of its storage organisations. This form of governance ensures that actors have adequate flexibility to adapt to the uncertainty surrounding crops (unpredictable environmental and behavioural aspects), while providing them with guarantees (quantity and price guaranteed prior to sowing). It also supports a dynamic of creating and exchanging the technical knowledge necessary for production. By reducing behavioural uncertainty, signing production contracts encourages intangible investments coordinated among farmers (experimentation), storage organisations (training of technical and business actors and the acquisition of internal agronomic benchmarks) and the industrial firm (R\&D), thus contributing to renewing the knowledge available on the crop. Furthermore, the governance of contracts is based on face-to-face interactions multiple times per year, facilitating the transmission and exchange of knowledge. During negotiations within the association, collectively defining contractual requirements regarding plant choices and production conditions supports the exchange of technical knowledge between storage organisations, in relation to the manufacturer's requirements concerning the technological qualities of the fava beans. Annually holding events bringing together farmers under contract also contributes to the exchange of experiences between farmers belonging to competing collection structures. Last of all, production under contract contributes to the acquisition of benchmarks relating to technical itineraries (by means of individual information sheets), which are analysed and then returned to the collective.

First of all, as the organisational forms at work imply a selection of stakeholders, it can in turn generate forms of exclusion. So, the status of the knowledge produced thanks to those organisational forms is neither totally private, nor public (which is characteristic of a club good (Buchanan 1965), so it limits the possibility of disseminating the knowledge to other territorial actors. This therefore raises the issue of the scope of the supply chains covered by the contracts, which is often that of niches, as in the case studied. Moreover, the agro-industrial nature of the supply chain reveals the underlying tension between the need for situated technical knowledge to diversify farmers' production systems, on the one hand, and the desire to standardise the products harvested in order to meet the requirements of industrial

survey we conducted on 20 cooperative leaders, in the large-scale cropping sector, in France, production contracts represent $0-40 \%$ of collection, according to organisations (Cholez et al. 2017). 
transformation, on the other hand. The collective governance of contracts on a production basin basis nevertheless contributes to the emergence of compromises around this tension. Lastly, structuring the conditions of the appropriability of the knowledge exchanged between members of the association is seldom discussed between these actors, but appears to be crucial in ensuring a long-term collective dynamic.

\section{Sensemaking in Management Situations Subject to Ambiguity and Uncertainty}

In the case of an AET, if we want to increase knowledge on the ins and outs of a new farming practice or on the best forms of learning and experimentation, this constitutes a case of reducing the uncertainty of the situation. If, on the contrary, we want to trigger a change in viewpoints so that certain farmers focus on different issues or see them differently (different target?), this constitutes a case of reducing ambiguity, in order, for example, to allow for action involving more cooperation based on the broader sharing of the meaning ascribed to the situation and of the target.

In the case of situations commonly considered "uncertain", management science provides an in-depth reflection on the concept of a situation. The term "situation" is commonly used in business and management language, often in a metaphorical sense. One must "control the situation", "become more familiar with the situation", address a "situation of crisis", a "complex situation", and so on. It is nonetheless interesting to move beyond this metaphorical approach to look at the scope of the notion of a situation (Journé and Raulet-Croset 2008), in particular to understand how it can shine light on individual or collective action.

In management science, the notion of a situation was proposed and elaborated by Jacques Girin (1990) to account for a specific category of situations, internal and external to organisations, which can be the subject of management analysis. From this angle, Girin uses three elements to describe the situation: "the participants, a space (the place or places where it takes place, the physical objects found there), and a time frame (a beginning, an end, a roll-out, and potentially a frequency)" (Girin 1990: 59). ${ }^{3}$ Introducing the purpose of the action, he proposes the situation we are dealing with to be considered a management situation when "the participants are united and must accomplish, in a determined time, a collective action leading to a result submitted to an external evaluation" (Girin 2011: 198). Actors internal to organisations, as well as other stakeholders such as suppliers or clients, can evaluate the engagement in a given situation.

Therefore, thinking in terms of situations enables one to identify their ingredients - the participants, the goal, the place or territory of action, the time frame, the evaluation - as well as their greater whole, the issue to which they relate, and the

\footnotetext{
${ }^{3}$ Our translation.
} 
meaning given to them. Therefore, a single given situation can be understood as a "whole" in different ways, which opens to a plurality of interpretations of the same situation. With regard to "sensemaking", Karl Weick (1995) differentiates the case of uncertain situations and that of ambiguous situations. The two are often presented as being similar, even though they do not relate to the same reality and call for different types of actions. According to him, "[i]n the case of ambiguity, people engage in sensemaking because they are confused by too many interpretations, whereas in the case of uncertainty, they do so because they are ignorant of any interpretations" (Weick 1995: 91). He therefore contrasts situations that are difficult to manage because they are the subject of multiple interpretations (ambiguous situations), with situations that are difficult to manage due to a lack of information or knowledge to understand them (uncertain situations). Accordingly, in the case of uncertainty, more information must be sought to be able to better deal with the problematic situation. In the case of ambiguity, there is no use in seeking more information, because the ambiguity is the result of the multiplicity of interpretations: "The problem in ambiguity is not that the real world is imperfectly understood and that more information will remedy that. The problem is that information may not resolve misunderstandings" (Weick 1995: 92).

When faced with an ambiguous situation, the collective action can therefore consist in triggering changes in interpretations and, for an actor that is a driver of a situation, in triggering changes in the ingredients of the situation or in enriching their interpretation thanks to the interpretations of others. Drawing inspiration from pragmatist approaches, we can consider that it is a matter of examining the reason behind the undetermined nature of the situation (Journé and Raulet-Croset 2008). According to Dewey, the components of a situation often "do not hold together". Inquiry is therefore the process that allows one to move past this initial indeterminacy to a point of possessing enough structure to allow a coherent and meaningful unit to emerge. The situation is thus progressively defined through the interplay of connections between objects, events, and individuals, forming a "contextual whole" (Dewey 1993), and evolves in line with the actions of each person: "what is designated by the word 'situation' is not a single object or event or set of objects or events. For we never experience nor form judgements about objects and events in isolation, but only in connection with a contextual whole. This latter is what is called a 'situation'. [...] In real life, these singular and isolated objects or events do not exist; an object or an event is always a part, a phase, or a particular aspect of an experienced surrounding world, that is, of a situation [...]" (Dewey 1938: 66).

In agroecology, situations of managing life forms are by nature very complex, and much research seeks to better understand the interactions within the system by reducing uncertainty in adding new knowledge. However, these can also be the subject of multiple interpretations, because the issue associated with them, and namely the meaning given to the actions to "manage" the situation, often does not come up. What is commonly referred to as "uncertainty" therefore sometimes corresponds to "ambiguity" as Weick defined it. Different actors that are stakeholders in a situation of managing the living world can provide different interpretations of the same situation. Uncertainty and ambiguity can also be linked. In uncertain situ- 
ations, additional knowledge can undoubtedly reduce uncertainty, but it can also enable a new interpretation of the situation. For example, understanding the influence of a farming practice in a territory or its effects on the environment does not necessarily make a problem considered from a technical angle obsolete, but it does enable other perspectives (territorial, environmental) of a problem. It is therefore up to the overseer/manager/person in charge of a situation to mobilise these different perspectives, either to enrich his or her own analysis of the facts or to construct a shared meaning, which despite being shared is liable to be a trade-off between multiple interpretations.

\section{Modelling Uncertainties to Design Management Methods}

After World War II, the mathematical modelling of decision-making emerged with Operations Research (Morse and Kimball 1951). Since then, it has experienced huge success in industrial production or services. Artificial Intelligence later extended its successes to decision-making problems involving the resolution of combinatorial problems that are more complex or that may require the implementation of learning methods (Sutton and Barto 1998).

In the domains of ecology and later agroecology, mathematical models to design management strategies emerged more recently (Wilson et al. 2006). This delay is mainly due to the significant uncertainty weighing down the dynamics of agroecosystems, as well as the interactions between biophysical practices and processes, which makes it complex to model them for management purposes. In the field of modelling, it is possible to distinguish two main sources of uncertainty in the input data for these models.

The first type of uncertainty, called "environmental", is a component of agroecological processes. In agronomics, crop models depend on "random" climate variables (temperatures, rainfall, etc.). Likewise, in ecology, changes in populations, communities, or meta-populations are uncertain because they are subject to uncontrollable aspects of the climate. This environmental uncertainty influences the effects of management methods in terms of yields, impacts on ecosystems, and so on. The second type of uncertainty is related to the quality of the observations, often referred to as partial observability. The modelling of the dynamics of agroecosystems under the effect of steering methods is made even more difficult by the fact that the evolution of these systems is observed with limited accuracy, or because not all of the elements of the system are observable. For example, the state of a crop's health of is often imperfectly observed, because the symptoms of a disease may be noticed late. Disregarding this latency can lead to poor disease management. The case of partial observation is clear in the example of a "seed bank", which is an element in the system that is currently not observed but which has a strong impact on the dynamics of the self-propagating plants in a crop. In this case as well, disregarding this aspect can lead to an abusive conclusion of eradicating the self-propagating species. 
Stochastic modelling enables the representation of these first two sources of uncertainty, but requires knowledge of the laws of probability. These probabilities may be unknown and difficult to evaluate. They may also evolve over time. For example, the effects of climate change on the biophysical processes involved in crop models, or those of socio-economic changes on prices, are only measured in "realtime" and not upstream at the time of their modelling to design cropping methods. The uncertainty "on" models is therefore combined with the two types of uncertainty "within" models, as mentioned above.

Due to the sequential aspect of decision making (annually, monthly, etc.) and the uncertainty surrounding and within models, it is natural to address the topic of designing agroecology management strategies from the perspective of research on adaptive management methods, as they are adaptive to the current state of the system and adaptive to new knowledge that will be acquired in the process (cf. adaptive management, Williams 2011). Over the past 30 years, various mathematical approaches have been developed to design strategies to manage agro-ecosystems under conditions of uncertainty, oriented towards either at ecology or agronomics, or very recently, agroecology (Tixier et al. 2013), by integrating ecological networks and ecosystem services into agronomic models (Mulder et al. 2018). All of these approaches address the sequential aspect, and the most sophisticated of them address the adaptation of decision-making to new knowledge.

These approaches have often been based on the Markov Decision Processes (MDP) framework (Puterman 1994), which seeks to optimise sequential decisions under uncertain conditions. It permits the optimised design of steering methods, where at each time step decisions are made on the actions to carry out as a function of the current observed states of the system. It is therefore suitable for taking into account the first type of uncertainty (explicitly modelled) surrounding the future dynamics of the agroecological processes managed. It allows the construction of adaptive strategies for which the action to choose over the time interval $t$ is only determined as of time $t-1$ as a function of the current state of the system, as opposed to defining action plans, which are determined in advance once and for all (cf., for example, Williams 2011). Following pioneering work on the use of MDP in farming and natural resource management (Kennedy 1986), the use of this framework was further developed in the domain of biodiversity conservation (Meir et al. 2004). It was then gradually spread by artificial intelligence researchers, in such a way as to take into consideration the different natures of uncertainty surrounding the input data of models, as mentioned above. For dealing with the uncertainty related to the partial observability of the state of the system, the extension of this framework to partially observable Markov decision processes (POMDP) was developed (it generated more complex mathematical problems) (Kaelbling et al. 1998). These POMDP were recently used in biodiversity conservation (Chadès et al. 2008). Reinforcement Learning (RL) approaches (Sutton and Barto 1998), often based on simulation, are suitable for solving problems related to the uncertainty surrounding the model of the system to manage. In this case, the implementation of management actions leads in turn to new observations of the system, which are useful for refining the model to 
better manage it. Reinforcement learning has been applied in the context of irrigation management (Crespo et al. 2011), for example.

The methodological tools to take uncertainty into consideration in modelling for agroecological design agroecological management methods are relatively mature. Several challenges nevertheless still have to be overcome. One of them is providing IT tools for modelling and designing management methods. Today, a few software toolboxes are available to modellers, dedicated to MDP, POMDP, and reinforcement learning for addressing spatialised management problems (cf. Chadès et al. 2014; Cros et al. 2017; Nicol et al. 2017 for examples of problems solved with these toolboxes). While the MDP framework is becoming increasingly known to agronomists and ecologists, the users of dedicated toolboxes still remain the modellers.

Finally, searching for management methods that respect a compromise between different ecosystem services generates problems, which continue to be difficult to resolve, in designing steering strategies, because they are the result of multi-criteria optimisation: the "values" of these different services are generally expressed in different, non-commensurable units (e.g. aesthetic value and gross margins). They cannot be aggregated into a single criterion to optimise, and in general, it is not possible to maximise all services simultaneously. To address adaptive decisionmaking issues on a multi-criteria basis, it is possible to use multi-criteria MDP approaches (e.g. Chatterjee et al. 2006), which are more difficult to solve than classic MDP.

\section{Jointly Modelling Uncertainty and Ambiguity to Explore the Potential of an Agroecological Innovation}

The French national action plan Ecophyto aimed at achieving a significant transition of French agriculture by cutting pesticide use by $50 \%$ within 10 years. Midterm evaluation shows mixed results (Potier 2014) and the final assessment was that of a failure (Guichard et al. 2017) since pesticide use even increased. A potential alternative to pesticides involves using biodiversity to stimulate pest regulation services (Duru et al. 2015b). Biological pest control using natural enemies is nonetheless often related to ecological processes on larger scales than farm management (Pelosi et al. 2010), particularly at the landscape scale (Alignier et al. 2014). Many landscape ecology studies specifically demonstrate the beneficial effect of a landscape rich in semi-natural habitats (hedgerows, woods, meadows, etc.) on these biological pest control ecosystem services (Bianchi et al. 2006; Veres et al. 2013). Thus, agricultural actors could potentially co-design a landscape rich in these habitats to favour related ecosystem services and coordinate their actions, thus facilitating natural pest regulation rather than pesticide use (Schellhorn et al. 2015). However, there are significant hindrances surrounding such an innovation and they require the consideration of different types of uncertainty. Uncertainties are associated both with the variability of results (Barrett and Dannenberg 2013) and with differences in stakeholders' viewpoints (Mathevet et al. 2011). For example, 
landscape ecology findings are variable when considering the agricultural benefits of landscapes rich in semi-natural elements (Bianchi et al. 2006), and tend to be implied more than actually proven (Griffiths et al. 2008). Ecologists therefore investigate the factors explaining such variability (Tscharntke et al. 2016). We refer here to two fundamental types of uncertainty as defined by Walker et al. (2003) in relation to their work on decision support models: epistemological uncertainty and ontological uncertainty. Epistemological uncertainty is due to a lack of knowledge that can be corrected, for example, by research or data acquisition. On the other hand, ontological uncertainty encompasses the inherent variability of processes whose randomness cannot be reduced by acquiring more knowledge. This can be likened to of a dice toss, the result of which remains random beyond the knowledge that each side has a likelihood of one in six.

To these initial types of uncertainty is added another distinct form of uncertainty: ambiguity. Ambiguity refers to the simultaneous presence of equally-valid viewpoints about an issue (Brugnach et al. 2011). A viewpoint is the representation of a given situation by an actor (Weick 1995). In our case representations are about how an agroecosystem functions. This type of uncertainty has been explored in particular in the field of decision-making in natural resource co-management, in which stakeholders with different viewpoints are involved. Including ambiguity is particularly relevant when collective actions are at play because the convergence and divergence of interacting viewpoints can influence the successes or failures of these collective actions (Janis 1971). Therefore, when the intention is to explore comanagement solutions, such as landscape-scale pest management, addressing the ambiguities of different stakeholders' viewpoint is critical.

The divergence or convergence status of different stakeholders' viewpoints can be reach by using Bayesian participatory modelling (Düspohl et al. 2012) adapted to the assessment of ambiguities (Salliou et al. 2017). Bayesian modelling explicitly takes ontological uncertainties into account because it is based on the elicitation of probabilities, thus integrating the variability of the phenomenon at stake. Ambiguity is taken into account by collecting probabilities specific to each actor, in order to parametrize a model structure common to all of them. Collecting and processing probabilities individually allows for a comparison of viewpoints. This is enabled by the fact that these individual probabilities are attached to a model structure (prior to parametrization) that has previously been co-constructed by actors in participatory collective workshops. This method is different from other participatory Bayesian modelling approaches that deal with ambiguities by integrating all viewpoints in a single parameterization (Henriksen et al. 2012). Keeping individual viewpoints apart enabled us to shed light on the convergence of actors regarding the low potential of using the landscape as a pest regulation tool. Beyond the ontological uncertainties described by each individual on ecological and social processes, the benefits of a landscape rich in semi-natural elements were always considered to be very limited.

This type of approach to uncertainties is particularly useful for an ex ante evaluation of the relevance of an agroecological innovation. Vuillot et al. (2016) have already pointed out the importance of really taking into account the representations 
of agricultural actors and farmers when creating public policies. Identifying innovation pathways fitting actors' interest in the agricultural world is essential to favour such innovation and potentially avoid significant failures like Ecophyto. This type of approach sheds light on the substantial gap often found between the intentions underlying public policies, and local representations.

\section{Discussion and Prospects}

These disciplinary and thematic clarifications are enough to demonstrate the diversity of notions of uncertainty used in research on the AET, whether in the case of strong or weak engagement, as noted by Angeon (cf. section "Understanding the agroecological transition as an economic situation of radical uncertainty"). This research clearly shows that the choice of one notion or another is derived from a specific stance with respect to uncertainty. Sometimes this stance is clearly anchored in a given discipline or school of thought, but the same notion can also be shared by different disciplines. Disciplines, via their concepts and methods, have constructed their own relationship to reality, complexity, and therefore uncertainty. However, our goal here was not to establish a typology of these notions by discipline, which would require more in-depth work both on the level of the epistemology of disciplines and on the ontology of each of the notions. Rather, we sought to shed light on the non-equivalency of these notions in their way of presenting and addressing uncertainty. By doing so, we can examine how these differences are related to different perspectives of the transition itself and its forms of support.

\section{Different Stances in Dealing with Uncertainty}

Through the elucidation of the definitions and ways of dealing with uncertainty used by the researchers whose work is discussed in this paper, it is possible to use the different notions to characterise three main types of relationship to uncertainty. The first relates to uncertainty that is considered environmental or exogenous to the system studied, but which has a varying degree of influence on this system. In this case, the relationship to uncertainty is distant: it is seen as something that is endured because the uncertainty is associated with external factors that are always beyond the actors' control and wishes. In this case, this uncertainty is a part of the context, which it is not possible to control, and not a part of the management situation described by Raulet-Croset (cf. section "Sensemaking in management situations subject to ambiguity and uncertainty"), to recall the distinction that Dewey makes between these two notions (Zask 2008). Ways of dealing with this environmental or contextual uncertainty vary and relate to different strategies for adapting to the unpredictable. Cholez (cf. section "Analysing new contractual forms as an organisational response to behavioural and technical uncertainties in agro-industrial 
diversification supply chains") presents environmental uncertainty (related to the climate or markets) as an element that cannot be quantified probabilistically, but that economic actors nonetheless take into account when they decide to coordinate with one another. It also constitutes a contextual element determining the type of coordination implemented in the new agroecological supply chains. Therefore, if uncertainty is present, forms with more coordination between actors will be sought. If uncertainty is low, the market will be the main factor in coordination. Other publications nonetheless attempt to describe this uncertainty in order to take it into account as a factor. For example, Sabbadin and Peyrard (cf. section "Modelling uncertainties to design management methods") describe how probability tools serve to describe this unpredictability in the form of random functions that it is possible to integrate into a modelled representation of the management system. In this case, environmental uncertainty is internalised.

Another relationship to uncertainty is built from knowledge on the objects and systems to be managed. This uncertainty emerges from a lack of information or knowledge on these objects, making their behaviour and their responses to actions unpredictable. Salliou et al. (cf. section "Jointly modelling uncertainty and ambiguity to explore the potential of an agroecological innovation") mention this uncertainty in ecological systems, whose organisation stems from a complex interplay between spatial and temporal interactions between a diversity of processes. They make use of the notion of ontological uncertainty to stress the fact that these behaviours will retain a certain amount of unpredictability, taking into account the incommensurability of the knowledge to produce in order to understand them. This uncertainty can be reinforced under the effect of environmental uncertainty in relation to factors directly affecting the dynamics of life forms. Reducing this uncertainty by producing knowledge on the mechanisms of the life forms at play nevertheless remains a goal. In this sense, Salliou et al. (cf. section "Jointly modelling uncertainty and ambiguity to explore the potential of an agroecological innovation") refer to the notion of epistemological uncertainty, in reference to Walker et al. (2003), who recall that uncertainty contains a component that may be at least partially reducible. Sabbadin maintains that this lack of knowledge is subjected to the limits of the observability of complex living systems, whose spatial and temporal organisation levels remain relatively intangible. The problem of measuring uncertainty in management is very directly related to the "quality" of the interplay between data as a prerequisite in a mathematical modelling process that aims at producing a robust (and not an accurate) representation of systems.

Lastly, a third category encompasses other research defining other types of uncertainty stemming from the actors themselves and the relationships that they maintain with objects, situations, and other actors. Therefore, differences in perspectives, goals, and knowledge but also in relationships to uncertainty itself are at play. This more subjective approach to uncertainty itself encompasses a diversity of proposals for addressing it, as the work presented in this chapter shows. Salliou et al. (cf. section "Jointly modelling uncertainty and ambiguity to explore the potential of an agroecological innovation") seek to elucidate the different viewpoints and representations of actors asked about the ability of the landscape to be able to regu- 
late agricultural pests. They use the notion of ambiguity from one actor to the next, which they liken to the notion of variability in relation to their Bayesian modelling process. Concretely, this modelling method allows them to integrate different viewpoints as a function of variability. By doing so, this allows them to evaluate the divergences and convergences in viewpoints among actors and the evolution of these viewpoints when placed in a situation of knowledge sharing. One hypothesis is that divergences in viewpoints of a system are more or less obstructive to the implementation of a collective action. On the other hand, Angeon (cf. section "Understanding the agroecological transition as an economic situation of radical uncertainty") presents the question of the uncertainty of the AET as an exploration process involving a wide diversity of actors and a process of combining knowledge on different scales of time and space. Sabbadin and Peyrard (cf. section "Modelling uncertainties to design management methods") also mention the uncertainty that emerges from researchers' own representations surrounding the operation of agroecosystems, which propagate errors in the modelling process and therefore the output of models.

From a management science perspective, Raulet-Croset (cf. section "Sensemaking in management situations subject to ambiguity and uncertainty") also uses the notion of ambiguity to account for the differences in understanding among actors involved in a management project. These differences are simultaneously anchored in different representations, aspirations, goals, and knowledge bases. The notion of a "situation" conveys the idea that instead of reducing this ambiguity (even if convergences emerge on the collective level), the goal should be to understand how this ambiguity plays a role in constructing the meaning of the action of a given group at a given time. In this case, the ambiguity is therefore defined in terms of a "here and now" management situation, and by nature is differentiated from the ambiguity defined by the management object itself as well as for representations of the landscape collected during individual interviews.

Still with respect to this third category, other approaches have been developed in the field of economics to deal with the uncertainty tied to the interaction between actors jointly involved in AET projects. These approaches aim at establishing organisations that are institutionalised to varying degrees and aim both at reducing the behavioural uncertainty of individuals and at adapting to exogenous environmental uncertainty. They seek to organise or even regulate the relations and exchanges between actors to work towards a given goal, whether by networking actors, as per Angeon (cf. section "Understanding the agroecological transition as an economic situation of radical uncertainty"), or drawing up contracts between them, as described by Cholez (cf. section "Analysing new contractual forms as an organisational response to behavioural and technical uncertainties in agro-industrial diversification supply chains"). This author thus describes new forms of contracts implemented for the creation of agroecological crop supply chains and that give more place to the transmission and sharing of technical knowledge as a factor in reducing behavioural uncertainty and stabilising agreements. 
It is clear from the different approaches detailed here that the diversity of notions is a result of differences in stances in understanding and dealing with uncertainty. They also demonstrate that differences can be identified within a single discipline or can be mobilised in dealing with a given subject matter. This is the case of the work of Salliou et al. (cf. section "Jointly modelling uncertainty and ambiguity to explore the potential of an agroecological innovation") on innovations on the landscape scale, in which a multidisciplinary research process involving elements simultaneously borrowed from ecology, social geography, and modelling attempts to mobilise two different points of entry and stances surrounding uncertainty, namely reducing the lack of knowledge on ecological systems and revealing ambiguities between actors. Inversely, different notions compete in reinforcing the same viewpoint of uncertainty. Nonetheless, this library of research is not capable of summarising the diversity of these stances on its own. In particular, considering uncertainty an opportunity and not a problem is not illustrated here. As mentioned by Cholez (cf. section "Analysing new contractual forms as an organisational response to behavioural and technical uncertainties in agro-industrial diversification supply chains"), other authors such as Pavitt (2005) or Gherardi (2008) acknowledge uncertainty or ambiguity as factors that are inherent to or even stimulating in innovation processes... In the context of transition studies, (Stirling 2014) addressed the topic of the diversity of innovation pathways for sustainable development by anchoring them in different relations to risk, ambiguity, uncertainty, and ignorance. For example, it is through this notion of ignorance - for him associated with the greater unknown within the field of possibilities - that he discusses adaptive learning as a source of systemic innovation and transformation. Research on the analysis and support of the AET has mainly sought to describe change processes. However, it is necessary to consider the obstacles and levers involved in these changes on different organisational levels (production systems, supply chains, the territory, etc.), as well as the trajectories and pathways of the transition, and in doing so, to consider methodologies for supporting actors in this transition.

\section{Different Perspectives on the Agroecological Transition and Its Issues}

This still incomplete description of the diversity of stances begs the question of their discussion in research on the AET. Due to its complexity, the AET implies management of uncertainty. The stance adopted with respect to uncertainty is rarely made explicit, and yet this choice of defining and dealing with uncertainty is directly related to the way of defining the AET and its issues. In this way, the fact of considering uncertainty a risk or an opportunity, of seeking to reduce it or to adapt to it, or of considering that progress will be the result of deepening knowledge on the objects to manage or of the capacity of actors to organise themselves and define that which 
is changing in their own situation, generates different perspectives on what the AET is, and on its levers.

Apart from qualifications of the "intensity" of the transition as being weak or strong (cf. section "Understanding the agroecological transition as an economic situation of radical uncertainty"), two perspectives of the transition process currently coexist and are the subject of debate in the scientific community. The first is described as deterministic and consists in achieving a relatively well-defined target, following the principles defined by agroecology. The precision with which this target is defined is often tied to the predetermination of the pathway and the process. The other perspective does not prejudge the state of the system to achieve, seeking instead to focus on the change process itself, that which it is capable of bringing on board as a dimension and triggering as a transformation along the way. These two perspectives are rooted in different representations or models of change that maintain relationships with uncertainty. In the first case, uncertainty is generally considered a risk of diverging from the goal. It therefore seeks to globally reduce this uncertainty whenever possible, to develop anticipation and forecasting, and to observe changing systems and capacities for reframing pathways. In the other case, the actors are the purveyors of the change. The uncertainty will be that which is felt, experienced, and managed by the actors themselves. Transformations in the system will be determined by the will and capacity of the different actors to collectively or individually organise. This perspective leaves more room for opportunity and surprise, even though the association between risk and uncertainty is still present. This initial interpretation should probably be nuanced inasmuch that these two perspectives - deterministic or indeterminate - both probably relate to a diversity of stances depending on the type of research undertaken.

This illustration raises the question however of the consequences of not elucidating these positions, despite the fact that multidisciplinary research is expected to address the issues of the AET. We believe that there is a risk tied to the ambiguity that may exist in mobilising different disciplines to address the different dimensions (social, ecological, technical, etc.) and objects involved in the transition, while omitting the lock-ins as well as the openings enabled by contrasting different perspectives on the relations between change and uncertainty. Controversies have emerged around these different perspectives, echoing tensions between life science, technological science, and social science approaches. Sometimes these approaches are simply incompatible, and at best can be made to coexist as different operational pathways for the AET. This raises a final question: to what extent is clarifying positions surrounding uncertainty capable of reinforcing this distancing or, on the contrary, of building a bridge to constructive dialogue in addressing issues pertaining to the transition? 


\section{References}

Alignier A, Raymond L, Deconchat M et al (2014) The effect of semi-natural habitats on aphids and their natural enemies across spatial and temporal scales. Biol Control 77:76-82. https://doi. org/10.1016/j.biocontrol.2014.06.006

Altieri MA (1999) The ecological role of biodiversity in agroecosystems. Agric Ecosyst Environ 74:19-31. https://doi.org/10.1016/S0167-8809(99)00028-6

Barrett S, Dannenberg A (2013) Sensitivity of collective action to uncertainty about climate tipping points. Nat Clim Chang 4:36-39. https://doi.org/10.1038/nclimate2059

Bianchi FJJA, Booij CJH, Tscharntke T (2006) Sustainable pest regulation in agricultural landscapes: a review on landscape composition, biodiversity and natural pest control. Proc R Soc B Biol Sci 273:1715-1727. https://doi.org/10.1098/rspb.2006.3530

Boltanski L, Thevenot L (1991) De la justification. Les économies de la grandeur., NRF Essais

Brousseau E, Glachant JM (eds) (2008) New institutional economics: a guidebook. Cambridge University Press, Cambridge

Brugnach M, Dewulf A, Henriksen HJ, van der Keur P (2011) More is not always better: coping with ambiguity in natural resources management. J Environ Manag 92:78-84. https://doi. org/10.1016/j.jenvman.2010.08.029

Buchanan J (1965) An economic theory of club. Economica 32:1-14

Chadès I, McDonald-Madden E, McCarthy MA et al (2008) When to stop managing or surveying cryptic threatened species. Proc Natl Acad Sci 105:13936-13940

Chadès I, Chapron G, Cros MJ et al (2014) MDPtoolbox: a multi-platform toolbox to solve stochastic dynamic programming problems. Ecography (Cop) 37:916-920. https://doi.org/10.1111/ ecog.00888

Chatterjee K, Majumdar R, Henzinger TA (2006) Markov decision processes with multiple objectives. In: Annual symposium on theoretical aspects of computer science. Springer, Berlin/ Heidelberg, pp 325-336

Cholez C, Magrini MB, Galliano D (2017) Field crop production contracts. Incentives and coordination under technical uncertainty, in French cooperatives. Économie Rural 365:65-83. https:// doi.org/10.4000/economierurale.5260

Crespo O, Bergez JE, Garcia F (2011) P2 hierarchical decomposition procedure: application to irrigation strategies design. Oper Res 11:19-39. https://doi.org/10.1007/s12351-009-0040-z

Crevoisier O, Jeannerat H (2009) Territorial knowledge dynamics: from the proximity paradigm to multi-location milieus. Eur Plan Stud 17:1223-1241. https://doi. org/10.1080/09654310902978231

Cros MJ, Aubertot JN, Peyrard N, Sabbadin R (2017) GMDPtoolbox: a matlab library for designing spatial management policies. Application to the long-term collective management of an airborne disease. PLos One 12(10):e0186014

Dewey (1938) Logic: the theory of inquiry. Henry Holt and Company, New York

Dewey J (1993) Logique. La théorie de l'enquête, (première édition 1938). PUF, Paris

Duru M, Fares M, Therond O (2014) Un cadre conceptuel pour penser maintenant (et organiser demain) la transition agroécologique de l'agriculture dans les territoires. Cah Agric 23:84-95

Duru M, Therond O, Fares M (2015a) Designing agroecological transitions: a review. Agron Sustain Dev 35:1237-1257. https://doi.org/10.1007/s13593-015-0318-x

Duru M, Therond O, Martin G et al (2015b) How to implement biodiversity-based agriculture to enhance ecosystem services: a review. Agron Sustain Dev 35:1259-1281. https://doi. org/10.1007/s13593-015-0306-1

Düspohl M, Frank S, Doell P (2012) A review of Bayesian Networks as a participatory modeling approach in support of sustainable environmental management. J Sustain Dev 5:1-18. https:// doi.org/10.5539/jsd.v5n12p1

Gherardi S (2008) « aujourd'hui les plaques sont molles!». Savoir situé et ambiguïté dans une communauté de pratiques. Rev d'anthropologie des connaissances 2(1):3-35. https://doi. org/10.3917/rac.003.0003 
Girard N, Magda D (2016) L432a: "Monograph of the relation between action, uncertainty and knowledge and of the modalities of natural resources qualification for each investigated collective actions" renommé "Analyse des principaux éléments de débats suite au séminaire organisés". Toulouse, p 156

Girel M (2016) Science et territoires de l'ignorance. Quae, Coll, Versailles

Girin J (1990) Problèmes du langage dans les organisations. In: Chanlat JF (ed) L'individu dans l'organisation. Les dimensions oubliées. Editions E. Québec, Québec, pp 37-77

Girin J (2011) Empirical analysis of management situations: elements of theory and method. Eur Manag Rev 8:197-212. https://doi.org/10.1111/j.1740-4762.2011.01022.x

Godard O (2001) Le développement durable et la recherche scientifique ou la difficile conciliation des logiques de l'action et de la connaissance. In: Jollivet M (dir) Le développement durable, de l'utopie au concept. De nouveaux chantiers pour la recherche. Elsevier (Coll. Environnement/ NSS), Paris, pp 61-81

Griffiths GJK, Holland JM, Bailey A, Thomas MB (2008) Efficacy and economics of shelter habitats for conservation biological control. Biol Control 45:200-209. https://doi.org/10.1016/j. biocontrol.2007.09.002

Guichard L, Dedieu F, Jeuffroy MH et al (2017) Ecophyto, the French action plan to reduce pesticide use: a failure analyses and reasons for hoping. Cah Agric 26:14002. https://doi. org/10.1051/cagri/2017004

Hatchuel A, Weil B (1992) L'expert et le système. Gestion des savoirs et métamorphose des acteurs dans l'entreprise industrielle. In: Economica

Henriksen HJ, Zorrilla-Miras P, de la Hera A, Brugnach M (2012) Use of Bayesian belief networks for dealing with ambiguity in integrated groundwater management. Integr Environ Assess Manag 8:430-444. https://doi.org/10.1002/ieam.195

Holling CS (1978) Adaptive environmental assessment and management. Wiley, Chichester

Holling CS, Meffe GK (1996) Command and control and the pathology of natural resource management. Conserv Biol 10:328-337

Horlings LG, Marsden TK (2011) Towards the real green revolution? Exploring the conceptual dimension of a new ecological modernisation of agriculture that couls "feed the worl". Glob Environ Chang 21:441-452. https://doi.org/10.1016/j.gloenvcha.2011.01.004

Hubert B (2002) Sustainable development: think forward and Act now, Paris, France

Janis I (1971) Groupthink. Psychol Today 5:43-46, 74-76

Jensen ES, Peoples MB, Hauggaard-Nielsen H (2010) Faba bean in cropping systems. Field Crop Res 115:203-216. https://doi.org/10.1016/j.fcr.2009.10.008

Journé B, Raulet-Croset N (2008) Le concept de situation: contribution à l'analyse de l'activité managériale dans un contexte d'ambiguïté et d'incertitude. M@n@gement 11:27-55. https:// doi.org/10.3917/mana.111.0027

Kaelbling LP, Littman ML, Cassandra AR (1998) Planning and acting in partially observable stochastic domains. Artif Intell 101:99-134. https://doi.org/10.1016/S0004-3702(98)00023-X

Kennedy J (1986) Dynamic programming. Springer, Dordrecht

Keynes JM (1921) A treatise on probability, reprinted in the collected Writings, vol 8

Keynes JM (1936) La Théorie générale de l'emploi, de l'intérêt et de la monnaie (trad. De Largentaye). Payot, Paris

Mathevet R, Etienne M, Lynam T, Calvet C (2011) Water management in the Camargue Biosphere Reserve: insights from comparative mental models analysis. Ecol Soc 16:43

Meir E, Andelman S, Possingham HP (2004) Does conservation planning matter in a dynamic and uncertain world? Ecol Lett 7:615-622. https://doi.org/10.1111/j.1461-0248.2004.00624.x

Morse MP, Kimball GE (1951) Methods of operations research. MIT Press, Cambridge, MA

Motet G (2010) Le concept de risque et son evolution. Ann des Mines - Responsab Environ 57:3237. https://doi.org/10.3917/re.057.0032

Mulder C, Sechi V, Woodward G, Bohan DA (2018) Ecological networks in managed ecosystems: connecting structure to services. In: Moore JC, De Ruiter PCD, McCann KS, Wolters V 
(eds) Adaptive food webs: stability and transitions of real and model ecosystems. Cambridge University Press, New York, pp 214-227

Nicol S, Sabbadin R, Peyrard N, Chadès I (2017) Finding the best management policy to eradicate invasive species from spatial ecological networks with simultaneous actions. J Appl Ecol 54:1989-1999. https://doi.org/10.1111/1365-2664.12884

North DC (2005) Understanding the process of economic change. Princeton University Press, Princeton

Pahl-Wostl C, Holtz G, Kastens B, Knieper C (2010) Analyzing complex water governance regimes: the management and transition framework. Environ Sci Policy 13:571-581. https:// doi.org/10.1016/j.envsci.2010.08.006

Pavitt K (2005) Innovation processes. In: Fagerberg J, Mowery DC (eds) The Oxford handbook of innovation. Oxford University Press, Oxford, pp 86-114

Pelosi C, Goulard M, Balent G (2010) The spatial scale mismatch between ecological processes and agricultural management: do difficulties come from underlying theoretical frameworks? Agric Ecosyst Environ 139:455-462. https://doi.org/10.1016/j.agee.2010.09.004

Postel N (2008) Incertitude, rationalité et institution. Rev économique 59:265. https://doi. org/10.3917/reco.592.0265

Potier D (2014) Pesticides et agro-écologie - Les champs du possible

Puterman ML (1994) Markov decision processes: discrete stochastic dynamic programming. Wiley, New York

Roberts J (2013) Organizational ignorance: towards a managerial perspective on the unknown. Manag Learn 44:215-236. https://doi.org/10.1177/1350507612443208

Salliou N, Barnaud C, Vialatte A, Monteil C (2017) A participatory Bayesian Belief Network approach to explore ambiguity among stakeholders about socio-ecological systems. Environ Model Softw 96:199-209. https://doi.org/10.1016/j.envsoft.2017.06.050

Schellhorn NA, Parry HR, Macfadyen S et al (2015) Connecting scales: achieving in-field pest control from areawide and landscape ecology studies: connecting scales. Insect Sci 22:35-51. https://doi.org/10.1111/1744-7917.12161

Simon HA (1964) Rationality. In: Gould J, Kolb WL (eds) Dictionnary of social science. Free Press, Glencoe, pp 573-574

Simon HA (1978) Rationality as a process and a product of thought. Am Econ Rev 68:1-16

Stirling A (2014) From sustainability to transformation: dynamics and diversity in reflexive governance of vulnerability. In: Hommels A, Mesman J, Bijker WE (eds) Vulnerability in technological cultures: new directions in research and governance. MIT Press, Cambridge, pp 1-61

Sutton RS, Barto AG (1998) Reinforcement learning: an introduction. MIT Press, Cambridge, MA

Thévenot L (1989) Équilibre Et Rationalité Dans Un Univers Complexe. Rev économique 40:147198. https://doi.org/10.2307/3502113

Tixier P, Peyrard N, Aubertot JN et al (2013) Modelling interaction networks for enhanced ecosystem services in agroecosystems. In: Woodward GO, Bohan DA (eds) Ecological networks in an agricultural world. Academic, Amsterdam, pp 437-480

Tscharntke T, Karp DS, Chaplin-Kramer R et al (2016) When natural habitat fails to enhance biological pest control - five hypotheses. Biol Conserv 204:449-458. https://doi.org/10.1016/j. biocon.2016.10.001

Veres A, Petit S, Conord C, Lavigne C (2013) Does landscape composition affect pest abundance and their control by natural enemies? A review. Agric Ecosyst Environ 166:110-117. https:// doi.org/10.1016/j.agee.2011.05.027

Voß JP, Bornemann B (2011) The politics of reflexive governance: challenges for designing adaptive management and transition management. Ecol Soc 16:9

Voß JP, Newig J, Kastens B et al (2007) Steering for sustainable development: a typology of problems and strategies with respect to ambivalence, uncertainty and distributed power. J Environ Policy Plan 9:193-212

Vuillot C, Coron N, Calatayud F et al (2016) Ways of farming and ways of thinking: do farmers' mental models of the landscape relate to their land management practices? Ecol Soc 21:35 
Walker WE, Harremoës P, Rotmans J et al (2003) Defining uncertainty: a conceptual basis for uncertainty management in model-based decision support. Integr Assess 4:5-17

Weick KE (1995) Sensemaking in organizations. Sage, Thousand Oaks

Williams BK (2011) Adaptive management of natural resources-framework and issues. J Environ Manag 92:1346-1353. https://doi.org/10.1016/j.jenvman.2010.10.041

Williamson OE (1996) The mechanisms of governance. Oxford University Press, Cary

Wilson KA, McBride MF, Bode M, Possingham HP (2006) Prioritizing global conservation efforts. Nature 440:337-340. https://doi.org/10.1038/nature04366

Yvrande-Billon A, Saussier S (2011) Economie des coûts de transaction. Editions L, Paris

Zask J (2008) Situation or context? A reading of Dewey. Rev Int Philos 245:313-328

Open Access This chapter is licensed under the terms of the Creative Commons Attribution 4.0 International License (http://creativecommons.org/licenses/by/4.0/), which permits use, sharing, adaptation, distribution and reproduction in any medium or format, as long as you give appropriate credit to the original author(s) and the source, provide a link to the Creative Commons licence and indicate if changes were made.

The images or other third party material in this chapter are included in the chapter's Creative Commons licence, unless indicated otherwise in a credit line to the material. If material is not included in the chapter's Creative Commons licence and your intended use is not permitted by statutory regulation or exceeds the permitted use, you will need to obtain permission directly from the copyright holder.

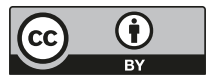

